
we derive the main lessons learned to date. ${ }^{1}$

The Ascension Health situation provides an excellent opportunity to examine the process of learning while designing organizations, and to adopt new ways of thinking about organization design. We agree with Dunbar and Starbuck (2006) who point out that future studies of organization design need to change in three ways from past studies: (1) start with a broader orientation that challenges both the design goals and design process rather than a traditional focus on alignment; (2) consider organization design as an ongoing process occurring over time rather than a one-off experience; and (3) emphasize a focus on emergent designs that are set up to expand action possibilities and create innovative responses to changing circumstances in particular environmental contexts, rather than adhering to general strategic plans that inevitably miss the mark in specific situations. This case highlights how Ascension Health's efforts to learn through the design process have generated emergent design possibilities and a continued experimentation with designs over time.

\section{ASCENSION HEALTH}

Ascension Health is the largest Catholic and largest not-for-profit healthcare provider in the United States. It provides a comprehensive array of healthcare services through 131 hospitals and more than 1,800 programs or care sites located in 24 states and the District of Columbia (see Figure 1 and Table 1). Ascension Health employs more than 150,000 associates, generates $\$ 21$ billion of annual revenue, and demonstrates its primary mission by providing nearly $\$ 1.5$ billion of annual healthcare for persons living in poverty and other vulnerable persons.

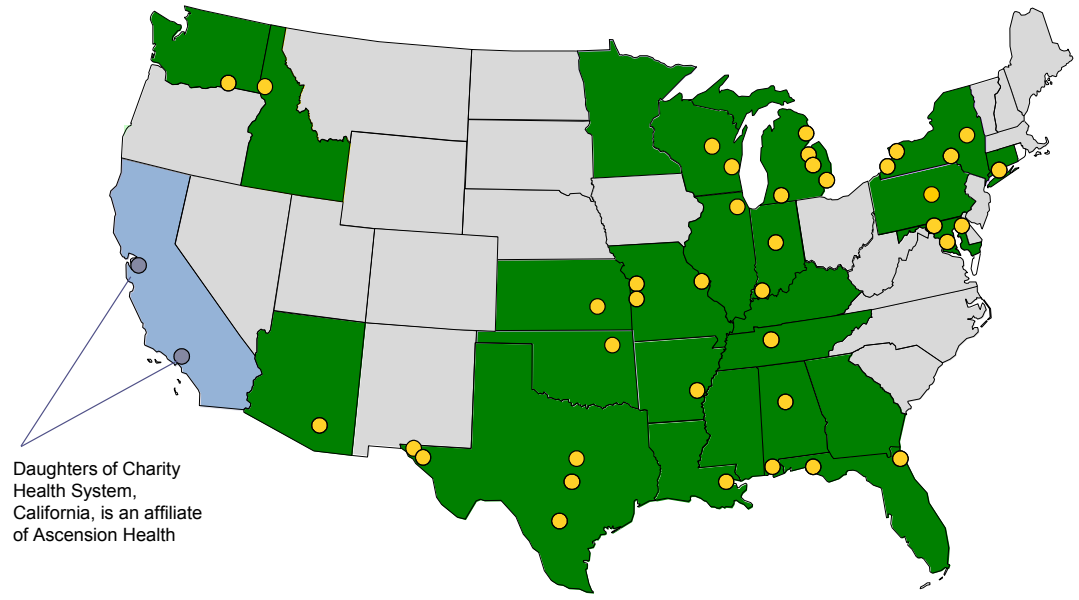

Fig. 1. Locations of Ascension Health Ministries

Ascension Health was established in 1999 and has grown through the integration of several healthcare systems sponsored by Catholic religious orders whose legacies of providing healthcare date back to the 1800s in the U.S. and centuries earlier in Europe. Ascension Health was formed by the 1999 union of the Daughters of Charity National Health System based in St. Louis, Missouri, and the Sisters of St. Joseph Health System based in Ann Arbor, Michigan. In 2002, Carondelet Health System joined Ascension Health, followed by Alexian Brothers Health System in 2012 and the Marian Health System in 2013.

In addition to this large healthcare delivery system, Ascension Health's parent organization, Ascension, owns and operates a number of organizations that provide services and solutions to Ascension Health and other healthcare providers throughout the U.S. Those organizations

1 All three authors are deeply involved in this case. Eric Engler is directing the Ministry Positioning process as Senior Vice President for Strategic Planning and Development of Ascension Health. In addition to being the Vernon Heath Professor of Organizational Innovation and Change at the Carlson School of Management at the University of Minnesota, Andrew Van de Ven is a member of the Ascension Health Board of Trustees and Chair of the Strategic Planning Committee that oversees the Ministry Positioning process. Stephen Jones is a Ph.D. candidate in the Carlson School of Management at the University of Minnesota who studies organizational learning, and he has worked closely with Van de Ven and Engler in preparing the case. Most of the data presented in the case come from Ascension Health sources. 
focus on services ranging from biomedical engineering, information technology, and supply chain management to financial services in venture capital and investment management.

Table 1. Types of Ascension Health Facilities and Services

\begin{tabular}{|l|c|}
\hline \multicolumn{2}{|c|}{ Hospitals by Type } \\
\hline General Acute Care & 103 \\
\hline Rehabilitation Hospitals & 3 \\
\hline Psychiatric Hospitals & 4 \\
\hline Long Term Acute Care Hospitals & 3 \\
\hline Joint Ventured Hospitals (<50\% ownership) & 18 \\
\hline
\end{tabular}

\begin{tabular}{|l|c|}
\hline \multicolumn{2}{|c|}{ Ambulatory Care and Diagnostics } \\
\hline Ambulatory Surgery Centers & 69 \\
\hline Occupational Health Programs & 49 \\
\hline On-Site Employer Clinics & 16 \\
\hline Free-standing Imaging Sites & 148 \\
\hline Retail Lab Collection Sites & 265 \\
\hline Primary Care Clinics & 371 \\
\hline Retail Pharmacy Sites & 42 \\
\hline Sleep Centers & 16 \\
\hline Virtual Care Programs & 63 \\
\hline \multicolumn{2}{|c|}{ Emergency Services } \\
\hline Urgent Care Sites & 46 \\
\hline Emergency Medical Services (EMS) & 28 \\
\hline
\end{tabular}

\begin{tabular}{|l|c|}
\hline \multicolumn{2}{|c|}{ Community Services } \\
\hline Mobile Clinical Services & 35 \\
\hline Wellness Centers & 20 \\
\hline Community and Social Programs & 162 \\
\hline Dispensary of Hope Sites & 82 \\
\hline Other Miscellaneous Services & 123 \\
\hline
\end{tabular}

\begin{tabular}{|l|c|}
\hline \multicolumn{2}{|c|}{ Post Acute Services } \\
\hline Durable Medical Equipment & 16 \\
\hline Home Health Services & 25 \\
\hline Hospice Services & 27 \\
\hline Outpatient Rehabilitation Centers & 188 \\
\hline
\end{tabular}

Ascension Health's vision is to be a strong, vibrant Catholic health ministry in the United States which will lead the transformation of the healthcare industry. Ascension Health is committed to the health and well-being of people in the communities it serves and responds to the health needs of individuals throughout their lives. It is committed to serving all persons, with special attention to those who are poor and vulnerable. Ascension Health's strategic direction for realizing this vision is to provide healthcare that is effective, safe, and leaves no one behind, for life.

\section{Organization Structure}

Ascension Health has 26 regional healthcare organizations, called Health Ministries, consisting of hospitals, physician practices, ambulatory services, long-term care and senior living, and other community-based healthcare services that are provided via an elaborate delivery model. Ascension Health's System Office, located in St. Louis, Missouri, and Ascension's service subsidiaries provide support resources and infrastructure to Health Ministries so that they can focus on determining and meeting local community needs. The Health Ministries collectively participate in setting system-level performance targets and are accountable to each other and the system as a whole for performance.

Ascension Health utilizes a model of distributed leadership that is rooted in the Catholic Social Teaching principle of subsidiary. As strategic and operational initiatives are explored, appropriate experts from across the system provide input to help shape the initiatives and how they will be implemented. Ascension Health's model of distributed leadership includes an authority matrix that specifies the roles of leaders and specialists throughout the system in making recommendations, approving actions, and implementing key decisions.

\section{Ministry Positioning Process}

In August 2012, Ascension Health launched a Ministry Positioning process as a means to assess the performance and strategic positioning of its 26 Health Ministries shown in Figure 1. The Ministry Positioning process was undertaken to address the confluence of internal and external forces that created urgency for Ascension Health to better understand the investments and partnerships needed to create sustainable organizations in each community served by a 
Health Ministry. Those various forces included:

- Ascension Health's strategic shift from episodic, acute care to person-centered care that is focused on individuals' broader health and well-being needs throughout their lives

- Momentum among physicians, providers (e.g., hospital, clinic), and payers/insurers towards value-based care and away from fee-for-service care

- Continuing constraints on capital availability and pressures on operating and financial performance

- Ongoing consolidation of hospitals/health systems and physician practices

- Uncertainty about healthcare industry trends that include unsustainable costs and prices, shifting revenue sources, entry of non-traditional competitors, emergence of informed consumers, and impact of clinical and information technologies.

The Ministry Positioning process was led by the Health Ministries with strategic and financial resources provided by the Ascension Health System Office. The process relied on Ascension Health's rich and diverse data sources and advanced analytics, models, and frameworks to develop an evidence-based understanding of the current position of each Health Ministry within its geographic market. It focused on generating future scenarios, developing strategic options, and identifying each Health Ministry's primary sustainable model for its region. The process was integrated into Ascension Health's strategic, operational, and financial planning processes to inform future investments. The process was also designed to provide a systemlevel view of the similarities and differences in market environments of the Health Ministries, and an understanding of the possible levels and reconfigurations of resources required to achieve sustainable models of healthcare in the communities served.

The Ministry Positioning work plan, illustrated in Figure 2, unfolded in four phases to answer a set of critical strategic questions.

Phase A: Profiles of Health Ministry Markets - This phase focused on developing an enhanced understanding of each Health Ministry's current market conditions and whether they would facilitate or impede the pursuit of Ascension Health's mission, its economic vitality, and its ability to transform the delivery of healthcare services in the communities served.

Phase B: Evaluate Competitors and Develop Future Scenarios - This phase involved developing an enhanced understanding of each Health Ministry's current performance and position compared to local competitors and to regional, system, and national benchmarks. It also identified plausible future market scenarios and disruptions.

Phase C: Determine Required Positioning/Assess Capabilities and Gaps - This phase identified the primary sustainable organizational model for each Health Ministry and assessed its current state of readiness and capability for developing its sustainable model.

Phase D: Develop Future Positioning Road Map - This phase focused on identifying the required investments, partnerships, or reorganizations necessary to develop each Health Ministry's sustainable model.

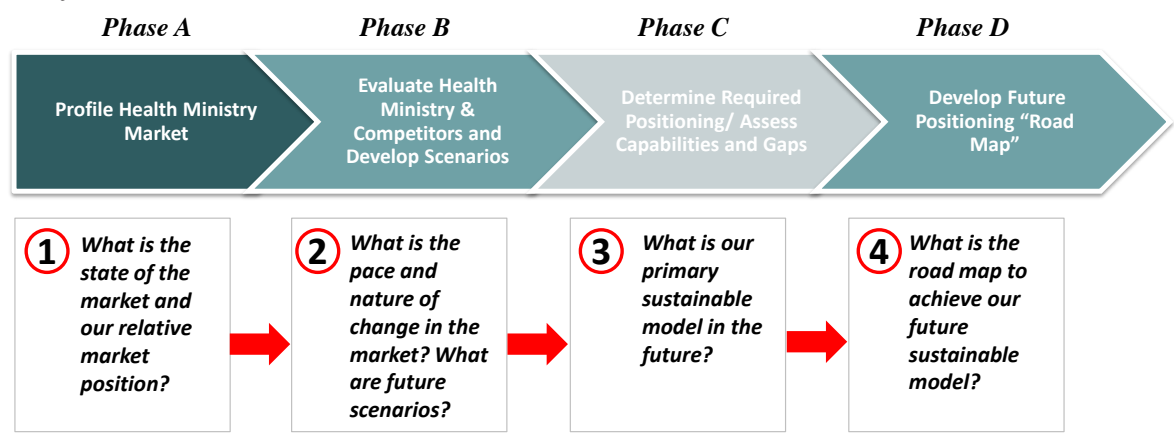

Fig. 2. Ministry Positioning Process

The Ministry Positioning process began with the selection of four Health Ministries to pilot the process. The four organizations were selected because of the rapidly changing market conditions in the communities they served as well as their diverse capabilities and market 
positions. This combination of factors provided opportunities to explore a variety of potential future scenarios and sustainable healthcare delivery models under very different market conditions. Based on experiences from the pilot program, the Ministry Positioning process was rolled out in the remaining 22 Health Ministries, with the entire process scheduled to conclude by December 2013.

\section{PRELIMINARY FINDINGS}

Since the Ministry Positioning process is still playing out, we can only share certain preliminary findings on the organization design implications for Ascension Health and its 26 regional healthcare organizations. These findings concern: (a) reconceptualizing healthcare markets based on the factors considered in the Phase A market assessment, (b) identifying sustainable organizational models of future healthcare delivery, (c) networking among organizations to create the scale and scope for managing a defined population of patients, (d) responding to the pace of market change, and (e) considering organizational performance based on the J-curve framework.

\section{Reconceptualizing the Healthcare Market}

To begin Phase A of the Ministry Positioning process, strategic planning staff at Ascension Health collaborated with each Health Ministry to define a regional market to serve as the basis for assessing initial market conditions and conducting the comparative performance and positioning analyses that are part of Phase B. Historically, Health Ministries defined their markets, or primary service areas, based on the contiguous set of ZIP codes from which approximately 75-80 percent of their hospital discharges originated. This approach to defining markets is relevant in an acute care-centric model, but it has drawbacks when considering strategic positioning and sustainable organizational models in a value-based healthcare delivery system where providers are responsible for patients across a larger geographic area and for services administered outside the hospital.

\begin{tabular}{|c|c|}
\hline $\begin{array}{l}\quad \text { Payer Environment } \\
\text { Commercial payer concentration } \\
\text { Commercial payer narrow network interest } \\
\text { Commercial value-based contracting } \\
\text { Penetration of Medicare Advantage } \\
\text { Penetration of Medicaid managed care } \\
\text { Health insurance exchange movement }\end{array}$ & $\begin{array}{l}\qquad \text { Physician Environment } \\
\text { Primary care supply \& demand } \\
\text { Specialty care supply \& demand } \\
\text { Physician community organization/dynamics } \\
\text { Prevalent physician alignment mechanisms } \\
\text { Physician community risk contract experience } \\
\text { Physician services pricing/compensation profile }\end{array}$ \\
\hline \multicolumn{2}{|l|}{ Self-insured employer engagement } \\
\hline $\begin{array}{l}\qquad \frac{\text { Continuum Services }}{\text { Environment }} \\
\text { Primary care landscape (clinics, FQHCs) } \\
\text { Ambulatory care landscape (ASCs, imaging, lab) } \\
\text { Post acute landscape (long term care, home } \\
\text { health, rehab, LTACH, hospice) } \\
\text { Behavioral health landscape } \\
\text { Prevalence of retail/urgent care/employer clinics } \\
\text { Community health services/infrastructure } \\
\text { Prevalence of telehealth/virtual care }\end{array}$ & $\begin{array}{l}\text { ity needs } \\
\text { yagement } \\
\text { y net }\end{array}$ \\
\hline
\end{tabular}

Fig. 3. U.S. Healthcare Market Conditions

Taking a regional, health-driven approach to defining markets requires consideration of not only a Health Ministry's acute care presence but also the geographic coverage provided by its physician enterprise, ambulatory network, and post-acute care services. In addition, it requires consideration of the size of the geographic area in which the critical mass of people needed to sustain the model live. When examined through this alternate market lens, certain Health Ministries do not currently have the strong regional presence required for future sustainability. 
Ascension's Health Ministries, and the markets in which they operate, are complex systems that are sensitive to initial conditions. Figure 3 outlines the initial market conditions examined through the Ministry Positioning process in the communities served, including the payer environment, physician environment, hospital/health system environment and the environment for other healthcare services across the continuum of care (e.g., ambulatory care, post-acute care). As Figure 3 shows, understanding these conditions requires a great deal of sophisticated analysis. The majority of the quantitative and qualitative information that informed the analysis of each Health Ministry's initial market conditions was obtained from proprietary data sources as well as from interviews with Health Ministry leaders and board members. This analysis provided Ascension Health and its Health Ministries with an enhanced understanding of each Health Ministry's initial market conditions and potential market disruptions that could influence its abilities to transform the delivery of healthcare services in its reconceptualized market.

\section{Sustainable Healthcare Delivery Models}

Phases A and B of the Ministry Positioning process were designed to inform the third phase of identifying future sustainable models for healthcare delivery in a region and for an assessment of current readiness and gaps in organizational capabilities. The first task of Phase $\mathrm{C}$ was for each Health Ministry to identify its primary model for future sustainability. While most Health Ministries cannot be exclusively tied to one model - and may indeed manage several models for risk-based and fee-for-service revenue streams - it was critical to identify a Health Ministry's "center of gravity" by way of a primary sustainable model going forward. To do this, the senior leaders of each Health Ministry engaged in a dialogue facilitated by Ascension Health strategists. In these meetings, participants discussed the current roles the Health Ministry played in its regional market and identified a preliminary model that it believed would be sustainable. Figure 4 presents the four basic models for sustainable healthcare delivery that emerged from these meetings, and Figure 5 summarizes the features of each model.

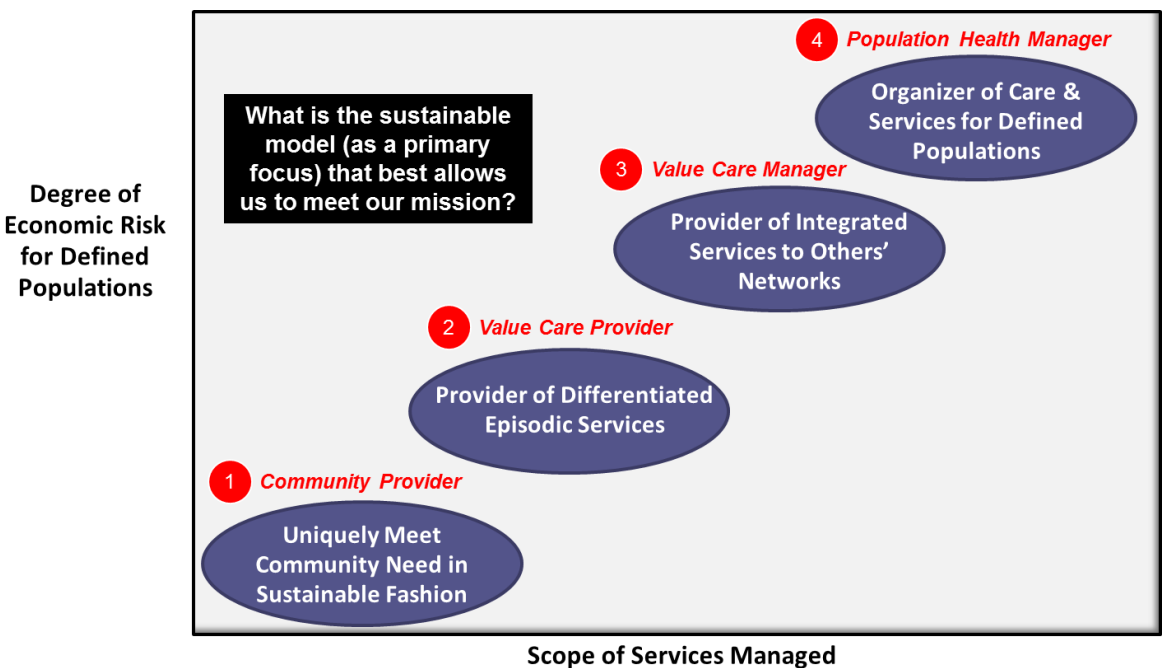

Fig. 4. Sustainable Healthcare Delivery Models

In the Community Provider model, a Health Ministry is positioned to uniquely meet one or more community needs in a sustainable fashion. Examples include being the sole provider of a key service or serving an unmet need or vulnerable population through a combination of traditional reimbursement, public subsidies, and private subsidies.

In the Value Care Provider model, a Health Ministry is positioned to provide services that are differentiated in terms of cost, quality, brand/reputation, and/or patient experience. This differentiation yields reimbursement and operating margin sufficient for ongoing sustainability. Examples include a hospital with a significant cost advantage relative to its peers, a clinical service like cancer care that is distinguished by its high-quality outcomes 
and reputation, or an ambulatory care center that is recognized for convenience and customer service.

\begin{tabular}{|c|c|c|c|c|}
\hline & $\begin{array}{l}\text { Community } \\
\text { Provider }\end{array}$ & $\begin{array}{l}\text { Value Care } \\
\text { Provider }\end{array}$ & $\begin{array}{l}\text { Value Care } \\
\text { Manager }\end{array}$ & $\begin{array}{c}\text { Population } \\
\text { Health Manager }\end{array}$ \\
\hline & $\begin{array}{c}\text { Uniquely Meet } \\
\text { Community Need in } \\
\text { Sustainable Fashion }\end{array}$ & $\begin{array}{c}\text { Provider of } \\
\text { Differentiated } \\
\text { Episodic Services }\end{array}$ & $\begin{array}{l}\text { Provider of } \\
\text { Integrated Services } \\
\text { to Others' Networks }\end{array}$ & $\begin{array}{l}\text { Organizer of Care \& } \\
\text { Services for Defined } \\
\text { Populations }\end{array}$ \\
\hline $\begin{array}{l}\text { Primary } \\
\text { Revenue } \\
\text { Sources }\end{array}$ & $\begin{array}{l}\text { Fee for Service } \\
\text { Public Subsidies } \\
\text { Private Subsidies }\end{array}$ & $\begin{array}{l}\text { Pay for Performance } \\
\text { Fee for Service }\end{array}$ & $\begin{array}{l}\text { Shared Savings } \\
\text { Bundled Payment } \\
\text { Fee for Service }\end{array}$ & $\begin{array}{l}\text { Capitation } \\
\text { Full Risk }\end{array}$ \\
\hline $\begin{array}{l}\text { Differentiation } \\
\text { Strategies }\end{array}$ & $\begin{array}{l}\text { Sole Provider of } \\
\text { Services } \\
\text { Meet Needs of } \\
\text { Vulnerable } \\
\text { Population(s) }\end{array}$ & $\begin{array}{l}\text { Low Cost Provider } \\
\text { Sole Provider of } \\
\text { Services } \\
\text { Regional/National } \\
\text { Recognition for Quality }\end{array}$ & $\begin{array}{l}\text { Coordinated Services } \\
\text { Across Continuum } \\
\text { Able to Demonstrate } \\
\text { High Quality at Low } \\
\text { Cost }\end{array}$ & $\begin{array}{l}\text { Scale to Effectively } \\
\text { Manage Risk } \\
\text { Targeted Interventions } \\
\text { for Defined Populations } \\
\text { Demonstrate Improved } \\
\text { Outcomes at Reduced } \\
\text { Cost }\end{array}$ \\
\hline
\end{tabular}

Fig. 5. Features of Sustainable Healthcare Delivery Models

In the Value Care Manager model, the Health Ministry is a provider of an integrated set of services, while participating as part of a larger service network to attract patients and insurers. The Health Ministry's role in the network revolves around its ability to deliver high-quality, low- cost healthcare services as well as its ability to contribute to other goals of the network.

In the Population Health Manager model, the Health Ministry is the organizer of care and services for defined populations. It has the scale to effectively manage risk and target interventions for high-risk patients to demonstrate improved outcomes and reduce the total cost of care.

Through the Ministry Positioning process, many Health Ministries learned that long-term sustainability would require a shift from Models 1 and 2 (Community Provider and Value Care Provider) to Models 3 and 4 (Value Care Manager and Population Health Manager).

\section{Networking to Create Scale and Scope}

Underlying the four healthcare delivery models is the recognition that stand-alone hospitals or other isolated healthcare providers will not be sustainable over the long-term. Rather, long-term sustainability requires healthcare providers to have the scale, geographic coverage, and access points required to serve the critical mass of covered patients in a valuebased healthcare environment. The importance of having a strong regional presence was accentuated through the Ministry Positioning process given: (a) the large intellectual, human, and financial capital requirements to transition from a volume-based model to a value-based model that often exceeds the resources of any single actor; (b) the shift from an independent, pluralistic view of physicians to an interdependent, integrated physician enterprise; (c) the need to reduce costs and rationalize services across healthcare delivery systems; and (d) the growing importance of creating a strong regional brand that is distinguished in the minds of payers, employers, and consumers.

Addressing these challenges requires designing organizations to respond to unique market conditions and at the proper scale. Given the diversity of markets and Health Ministry capabilities located in those markets, the Ministry Positioning process is now exploring the types of network organizations that are expected to be sustainable in providing the needed healthcare services in each market region. Designing such integrated healthcare networks blurs the boundaries between historically competing organizations and shifts the design problem to a higher level from the single organization to the collaborative network of organizations.

\section{Pace of Market Change}

One key analysis performed as part of the Ministry Positioning process was an assessment of the pace of change of the markets in which Ascension Health operates. The pace of change assesses the relative speed at which Health Ministry markets are transitioning to value-based 
healthcare delivery. In other words, markets were assessed for how quickly they are expected to shift from the current volume-based, episodic reimbursement model to a model that puts providers at economic risk for delivering integrated care that produces value for purchasers (i.e., high quality and better experience with lower overall cost). Pace of market change was assessed on several qualitative and quantitative factors using state and local data, including:

- Number of people in managed-care systems or other value-based arrangements

- Accountable Care Organization development

- Health insurance exchange development

- Market consolidation

- Market-driven clinical integration

- Overall healthcare cost pressures

- Accelerating/decelerating organizational events (e.g., a recent merger of two competitive healthcare systems).

The pace of change assessments and the resulting changes in payer mix, utilization, and reimbursement provided a consistent approach to modeling the impact of health reform and local market dynamics on the future financial performance of the Health Ministries. This led to a better understanding of the significant changes expected in revenue in the coming years, whether due to lower volumes with more utilization management, governmental reimbursement cuts, commercial rate compression, shifts to health insurance exchange coverage from uninsured or employed persons, and general demographic shifts such as the aging of the population.

As part of the evolution of the reimbursement system from primarily fee-for-service to value-based payment models, healthcare providers increasingly will have a portion of their revenues at risk based on their ability to deliver against cost, quality, and patient experience targets. However, the pace at which fee-for-service payment models will erode, and what specific types of risk-based arrangements will emerge, varies significantly by market. Figure 6 illustrates on the horizontal axis the relative pace of transition toward value-based payment models in the markets served by Ascension Health compared to the vertical depiction of the proportion of the Health Ministry's revenue projected to be in risk-based contracts by 2018 . As shown in Figure 6, the Ministry Positioning process helped the Health Ministry leaders and their advisory boards learn how fast their markets were changing, and they could set their strategies to respond to the pace of change.

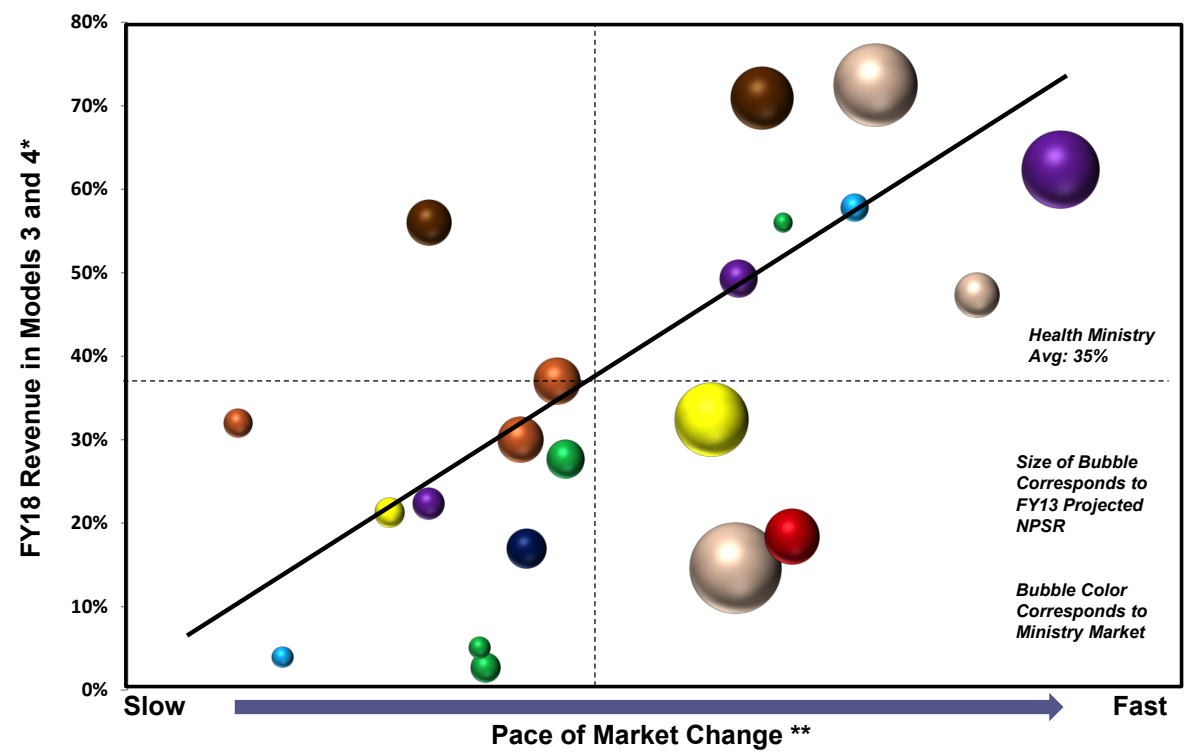

Fig. 6. Health Ministry Positioning and Pace of Market Change

For Health Ministries in faster-moving markets, the Ministry Positioning work has confirmed the need to create the organizational capabilities required to align independent and employed physicians and to capture the value created through delivering high-quality, low-cost, and 
clinically appropriate care. An innovative example is MissionPoint Health Partners (see Figure 7), which has organized a diverse and comprehensive set of healthcare professionals and facilities around each member in the network. The MissionPoint Health Partners physicians are helping members define and follow individual care plans, transition from the hospital to the home or other care settings, and change behaviors. For example, pharmacists perform medication reconciliation and therapy management for the most complicated members, and nutritionists are working with members facing new lifestyle and dietary constraints. All of these services have previously been in demand by physicians but have either been too difficult to coordinate across the continuum of care or have not been traditionally reimbursed.

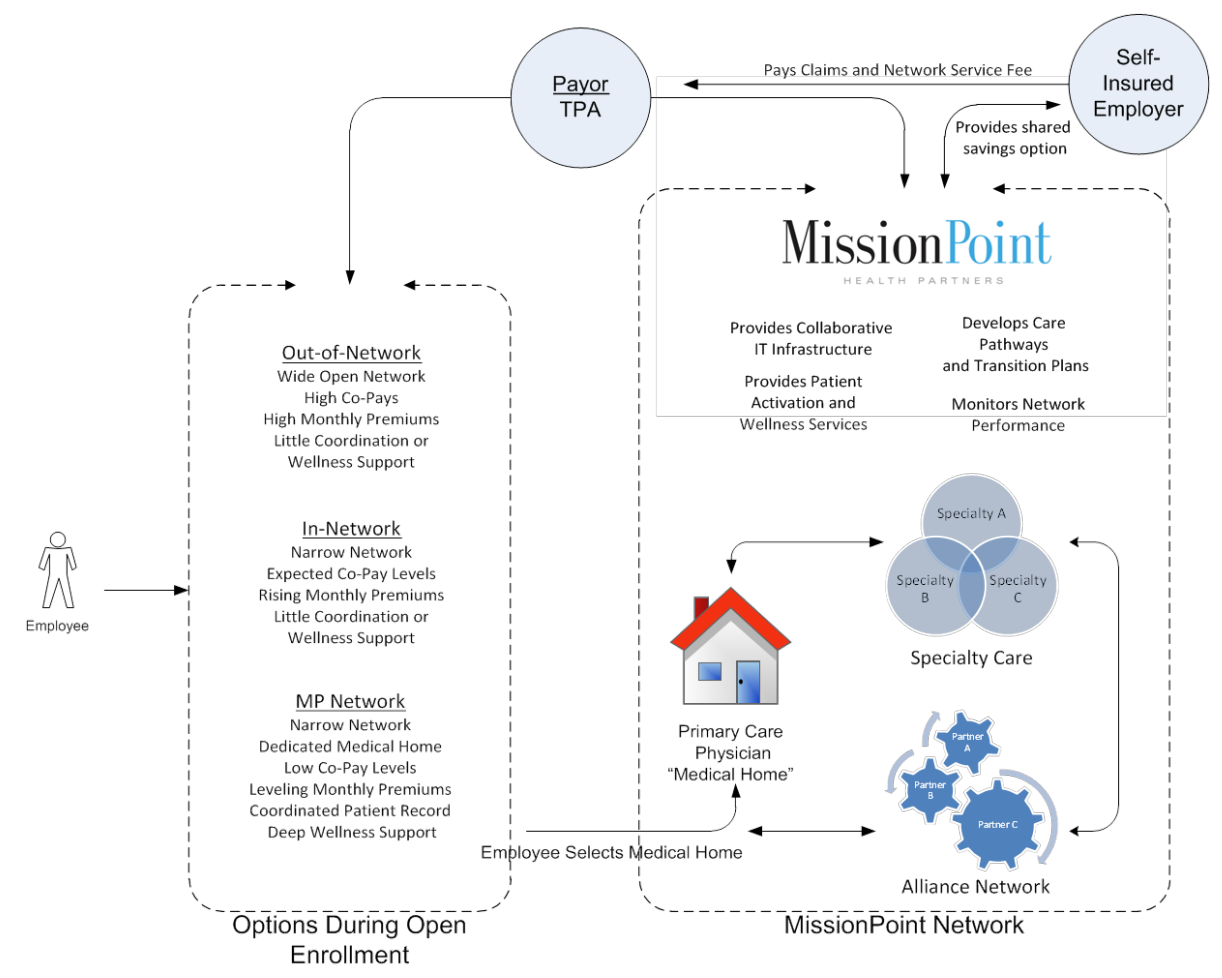

Fig. 7. MissionPoint Health Partners Structure

MissionPoint Health Partners is not an insurance carrier. Instead, it creates networks of physicians, hospitals, and other providers and supports the network through innovative capabilities to provide the highest quality care to each member. What sets MissionPoint Health Partners apart from most other clinically integrated networks, however, is that every contract with a payer or employer is based on the ability to improve healthcare quality and reduce costs. MissionPoint Health Partners is a new organization, but experience with it to date suggests that its innovative care and business models may be transferrable beyond the pilot location in Tennessee to serve other Health Ministries.

\section{J-curve Considerations of Ministry Positioning}

The J-curve shown in Figure 8 is used often in the private equity industry to illustrate the historical tendency of private equity funds to deliver negative returns in the early years due to costs incurred in starting the fund, and investment gains in the outlying years as the portfolios of companies mature and become more stable and profitable. The J-curve is also a helpful construct for thinking about the performance of organizations going through business model transformation, such as many of the Health Ministries will be doing. As healthcare systems commit to becoming value-based integrated delivery systems and assume the risks associated with managing the health outcomes and costs of defined populations, it will be necessary to invest in new capabilities and infrastructure and partner with healthcare purchasers to develop contracts that equitably reward healthcare systems for providing high-quality, lowcost care and reducing healthcare utilization. The investments that need to be made during 
this phase, along with the near-term impacts of reduced utilization, will not be completely offset by value shared through the at-risk contracts (e.g., shared savings). As healthcare systems learn how to better manage population health, performance will begin to head in a positive direction buoyed by better care management systems, lower cost structures, and additional revenue derived from serving new populations.

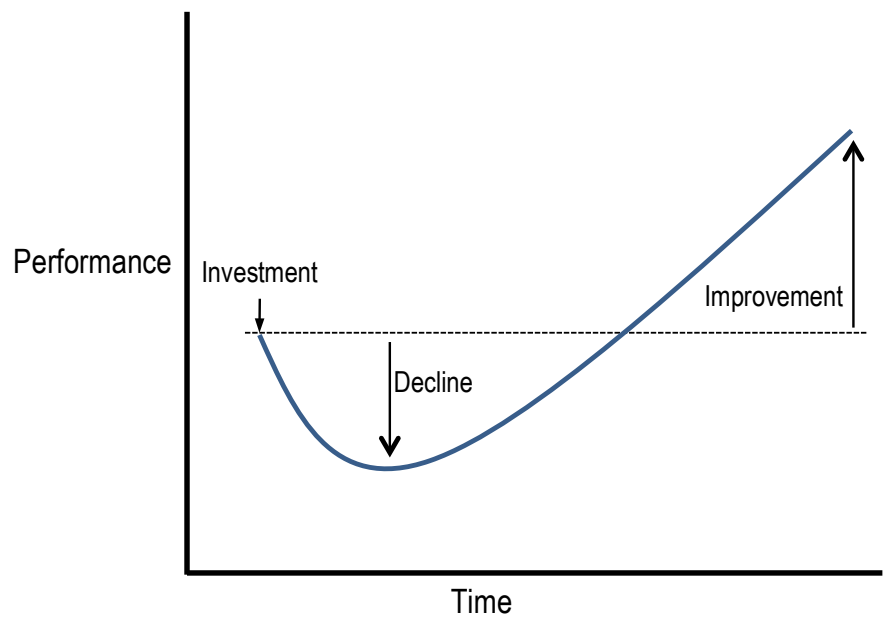

Fig. 8. Three Phases of the Performance J-curve

Depending on which Health Ministries are experiencing the J-curve at any one time, Ascension Health could experience a dip in financial performance as it transforms its business model in parts of the system. As Ascension Health seeks to sustain its financial stability through the transition to value-based healthcare delivery, it must consider means by which to flatten or narrow the shape of the J-curve. Such mitigating strategies may include but are not limited to:

- Staging investments in markets and Health Ministries to spread the impact of the J-curve over time

- Reducing population health management infrastructure investment costs (i.e., realizing the benefits of scale across Ascension Health)

- $\quad$ Partnering with the purchasers of healthcare to develop and deploy full-risk products that equitably reward quality improvement and total cost reduction

- Accelerating the capture of new populations and associated incremental volume through the expansion and alignment of physician/ambulatory care networks

- Securing the necessary capital to invest in population health management capabilities and infrastructure from non-traditional sources.

Ascension Health is exploring all of these approaches to manage the J-curve impact across its Health Ministry portfolio.

\section{LEARNING FROM DESIGNING}

The above findings are preliminary learning experiences gained from the Ministry Positioning process as it unfolded over the past 16 months. Although the process of redesigning the Health Ministry organizations is still underway, Ascension Health has gained a number of insights about the design process that we can share at this time.

Organizations learn about important design elements by engaging in dialogue and reflecting on their actions. Like Dunbar and Starbuck (2006), we believe that organization design theory, at its present stage of development, cannot adequately anticipate and encompass all of the complexities encountered in designing organizations. Many theories are needed to design organizations, and they become apparent as the design process evolves. Moreover, learning is accelerated when a diverse set of people are engaged and communicate their interpretations of unfolding events (Crossan, Lane, \& White, 1999; Orlikowski, 2002).

A goal orientation toward learning is an important catalyst for seeking feedback that is both positive and negative. Ascension Health leaders at all levels spurred learning by constantly seeking feedback. For instance, the minutes of quarterly meetings of the Board of Trustees Strategic Planning Committee from June 2012 to September 2013 record repeated 
questioning: What is being learned from the Ministry Positioning process? What learning can be transferred to other Health Ministries as they undertake the strategic positioning process? How can the process contribute to Ascension Health becoming a learning organization? Ascension Health's leaders were receptive and responded to such questions with reports of their findings in subsequent board meetings. Ascension Health leaders throughout the system pushed the organization to capture and internalize as much design knowledge as possible, clearly demonstrating a learning goal orientation (Ashford, Blatt, \& VandeWalle, 2003; Dweck, 1986).

Learning is facilitated by an organizational culture that emphasizes communal participation in developing and achieving collective goals. The Ministry Positioning process was organized to include numerous meetings and workshops involving Health Ministry leaders, Ascension Health leaders, staff, and board members. Health Ministry leaders, in turn, were encouraged to involve patients, providers, and key stakeholders in their local communities in the process. These groups often interpreted the same events differently, but an open and trusting environment existed that triggered learning. Trust was fostered by the actions of Ascension Health leaders. They helped direct attention to the collective goal of advancing Ascension Health's vision to be a vibrant Catholic health ministry that serves the community, particularly the poor and vulnerable. Bunderson and Reagans (2011) stress the importance of a collective orientation among organizational leaders for learning to occur. They argue that learning roadblocks occur when leaders focus on their individual (as opposed to collective) values and goals, and when the balance of power among the parties involved is unequal. Ascension Health leaders emphasized collective goals and used their influence to create a safe environment for employees and managers to contribute.

Learning is more penetrating when it relies on evidence rather than opinion. This is not to suggest that opinions and theories are not important, for they certainly are. However, learning is more likely to occur when it is based on reliable data or evidence than when it is based solely on philosophical arguments. This is because the discussion of evidence provides a more objective means of reflecting on and arbitrating differences of opinions among parties (Briner, Denyer, \& Rousseau, 2009). Data obtained through the Ministry Positioning process certainly is helping Ascension Health leaders analyze their current situation, and better understand similarities and differences with other healthcare systems in their local regions and with other Health Ministries. Ascension Health treats the specific strategies in different Health Ministry markets as "portfolios of experiments", and this allows managers to make evidence-based decisions in assessing progress along their strategic path and to make further design changes as the process unfolds. By synthesizing learnings from multiple Health Ministries in different market environments, Ascension Health can develop knowledge that is useful for Health Ministries across the system. Moreover, the roll-out of new positioning strategies is occurring at different times for different Health Ministries. This provides opportunities to transfer learning from lead Health Ministries to later Health Ministries with similar conditions.

Forging collaborative relationships is an effective way of exploring turbulent environments. The MissionPoint Health Partners network showcases the importance of developing collaborative relationships in the broader network. This collaborative network, consisting of payers, physicians, and other healthcare providers, will be critical for developing sustainable models of healthcare delivery. These relationships have the potential to continue to promote learning and adaptation as the healthcare organizations evolve in their turbulent environment (Kraatz, 1998).

Learning must keep pace with the rate of change. Although the characteristics of turbulent environments have been known for some time (Emery \& Trist, 1965), their implications for designing organizations have received little attention (Dunbar \& Starbuck, 2006). As shown in Figure 6 above, data from the Ministry Positioning process found a strong positive association between the pace of market change and projected revenue from integrated healthcare organizations or networks participating in value-based services. As would be expected, organizational arrangements become more temporary, flexible, and improvisational as the pace of market change increases. This implies that learning in organizations must keep pace with the speed of environmental change (Dodgson, 1993). But this relationship may also 
work in reverse. The pace of market change should also increase the pace of organizational learning because it speeds up cycles for trial-and-error learning. As a result, fast-moving environments may provide the best laboratories for rapid organizational learning. Continuing study of Ascension Health and its Ministry Positioning process may shed further light on this relationship.

\section{CONCLUSION}

Healthcare organizations provide a useful setting for advancing our knowledge of organization design. The unsustainability of many current organizational arrangements, the complexity of providing healthcare, and the pace of market change render simple design paradigms unviable. The Ascension Health case offers a glimpse into one industry participant's efforts to incorporate learning into its design process. And while the knowledge that Ascension Health is gaining is idiosyncratic, the case provides broader insights about learning while designing organizations. Specifically, the case highlights the need to have broad engagement in the learning process and to create an open atmosphere for dialogue. Also, evidencebased feedback and a portfolio of design experiments are particularly valuable mechanisms for gaining design insights. Finally, important design insights come not only from within organizations; they also occur as organizations develop relationships with other relevant actors in the larger organizational domain.

Acknowledgements: We greatly appreciate the many helpful comments we received from participants when we presented the Ascension Health case at the Organizational Design Community's annual conference in Lake Buena Vista, Florida on August 8, 2013. We also thank Charles Snow for his helpful editorial advice.

\section{REFERENCES}

Ashford SJ, Blatt R, VandeWalle D. 2003. Reflections on the looking glass: A review of research on feedback-seeking behavior in organizations. Journal of Management 29(6): 773-799.

Briner RB, Denyer D, Rousseau DM. 2009. Evidence-based management: Concept cleanup time? Academy of Management Perspectives November: 19-22.

Bunderson JS, Reagans RE. 2011. Power, status, and learning in organizations. Organization Science 22(5): 1182-1194.

Crossan MM, Lane HW, White RE. 1999. An organizational learning framework: From intuition to institution. Academy of Management Review 24(3): 522-537.

Dodgson M. 1993. Organizational learning: A review of some literatures. Organization Studies 14: 375-394.

Dunbar RLM, Starbuck WH. 2006. Learning to design organizations and learning from designing them. Organization Science 17: 171-178.

Dweck CS. 1986. Motivational processes affecting learning. American Psychologist 41(1): 1040-1048.

Emery F, Trist E. 1965. The causal texture of organizational environments. Human Relations 18: 21-32.

Kraatz MW. 1998. Learning by association? Interorganizational networks and adaptation to environmental change. Academy of Management Journal 41(6): 621-643.

Orlikowski WJ. 2002. Knowing in practice: Enacting a collective capability in distributed organizing. Organization Science 13(3): 249-273.

Plsek P, Greenhalgh T. 2001. The challenge of complexity in health care. British Medical Journal 323: 625-628.

Porter ME. 2009. A strategy for health care reform - toward a value-based system. The New England Journal of Medicine 361(2): 109-112.

Schoen C, Osborn R, Squires D, Doty M, Pierson R, Applebaum S. 2012. How health insurance design affects access to care and costs, by income, in eleven countries. Health Affairs 29(12): 2323-2334. 


\section{ERIC S. ENGLER}

Senior Vice President, Strategic Planning and Development Ascension Health

E-mail: eengler@ascensionhealth.org

\section{STEPHEN L. JONES}

Ph.D. Candidate

Carlson School of Management, University of Minnesota

E-mail: jone2093@umn.edu

\section{ANDREW H. VAN DE VEN}

Vernon Heath Professor of Organizational Innovation and Change

Carlson School of Management, University of Minnesota

E-mail: avandeve@umn.edu 